\title{
The Near Term Growth Impact of the Tax Cuts and J obs Act
}

Ka rel Mertens

Federal Reserve Bank of Dallas Research Department Working Paper 1803 https:// doi.org/10.24149/wp1803 


\title{
THE NEAR TERM GROWTH IMPACT \\ OF THE TAX CUTS AND JOBS ACT*
}

\author{
KAREL MERTENS \\ Federal Reserve Bank of Dallas
}

mertens.karel@gmail.com

\section{March 23, 2018}

\begin{abstract}
This note uses existing empirical estimates of the macroeconomic effects of tax changes to project the near term impact of the Tax Cuts and Jobs Act on US GDP growth. Applying recent reduced form estimates of tax multipliers with the projected revenue impact of the Act yields a level of GDP that is predicted to be $1.3 \%$ higher by 2020, with most of the growth front-loaded in 2018. Accounting for the composition of the Act in terms of its individual and corporate provisions leads to a similar GDP increase by 2020, but with stronger growth in 2018 and a partial reversal in the following years. Accounting for the impact of TCJA on marginal individual tax rates raises the projected growth impact considerably, while accounting for the distribution of the tax changes across income groups suggests a more delayed positive impact on GDP. These projections are conditional on meanreverting dynamics of future taxes that are estimated from postwar US data.
\end{abstract}

Keywords: Fiscal Policy, Taxation, Tax Cuts and Jobs Act

JEL Classifications: E62, H2

\section{The TAx Cuts And Jobs ACT}

The Tax Cuts and Jobs Act (TCJA), signed into law by the President on December 22, 2017, substantially cuts statutory tax rates for individuals and pass-through businesses until 2025, and permanently lowers the statutory tax

*The views in this paper are those of the author and do not necessarily reflect the views of the Federal Reserve Bank of Dallas or the Federal Reserve System. I am grateful to Dario Caldara, Tyler Goodspeed, Jason Furman, Jason Saving and Owen Zidar for comments, but all responsibility including for any errors or omissions lies exclusively with the author. 
rate for corporations from $35 \%$ to $21 \% .^{1}$ The Act also replaces a worldwide tax system, subjecting all income of US businesses earned globally, with a territorial tax system, subjecting all income of domestic and foreign corporations earned within US borders.

TABLE I

STATIC BUDGET IMPACT OF TCJA

\begin{tabular}{|c|c|c|c|c|c|}
\hline & Fiscal Year & 2018 & 2019 & 2020 & $2018-27$ \\
\hline \multirow[t]{2}{*}{ Total } & Billions \$ & -136 & -280 & -259 & $-1,456$ \\
\hline & $\begin{array}{l}\text { As } \% \text { of } \\
\text { GDP in } 2017[1]\end{array}$ & -1.1 & -1.4 & -1.3 & -7.5 \\
\hline \multirow[t]{2}{*}{ Individual Tax Reform } & Billions \$ & -75 & -189 & -172 & $-1,126$ \\
\hline & $\begin{array}{l}\text { As } \% \text { of PI } \\
\text { in } 2017[1][2]\end{array}$ & -0.8 & -1.2 & -1.1 & -7.5 \\
\hline \multirow[t]{2}{*}{ Business Tax Reform } & Billions \$ & -129 & -134 & -113 & -654 \\
\hline & $\begin{array}{l}\text { As } \% \text { of CI } \\
\text { in } 2017[1][3]\end{array}$ & -7.4 & -5.8 & -4.9 & -29.5 \\
\hline \multirow[t]{2}{*}{ International Tax Reform } & Billions \$ & 69 & 43 & 26 & 324 \\
\hline & $\begin{array}{l}\text { As } \% \text { of CI } \\
\text { in } 2017[1][3]\end{array}$ & 3.6 & 1.7 & 1.2 & 14.7 \\
\hline
\end{tabular}

Notes. Budget impact numbers are the conventional estimates from the Joint Committee on Taxation December 18, 2017 (JCX-67-17). NIPA data are from the January 26, 2018 release by the Bureau for Economic Analysis. [1] Converted into calendar year estimates by assigning 25 percent of the subsequent fiscal year to the current calendar year. [2] PI is personal income tax base defined as in Mertens and Ravn (2013) as NIPA personal income less transfers plus contributions for social insurance. [3] Corporate income (CI) is based on NIPA corporate profits as defined in Mertens and Ravn (2013).

Table I provides estimates of the budget impact of the 2017 Act in each of the next three fiscal years, as well as over the next decade. The budget estimates are from the December 18 report of the Joint Committee of Taxation, a nonpartisan committee of the US Congress, and deliberately do not incorporate macroeconomic feedback effects. ${ }^{2}$ Without such feedback effects, TCJA is projected to lower revenues by a cumulative total of almost $\$ 1.5$ trillion

\footnotetext{
1 "Tax Cuts and Jobs Act" was the original name of the proposed legislation but was removed in the final version.

${ }^{2}$ The calculations by the Joint Committee staff make use of a large sample of confidential IRS tax returns and a number of supplementary data sources. The calculations are based on the assumption that the tax reform does not change gross national product from the pre-reform baseline provided by the Congressional Budget Office, but the Joint Committee staff does incorporate certain behavioral effects, including shifts in economic activity across sectors or in the timing of such activity in response to the tax change. See: https://www. jct.gov/ about-us/revenue-estimating.html.
} 
dollars over the next decade. Assuming an annual growth rate of nominal GDP of 4 percent, this adds roughly 5 percentage points to outstanding debt as a percentage of GDP. Because of sunset provisions, about half of the total revenue loss occurs in the first three years after enactment. This results in a total tax cut of 3.7 percent of GDP at 2017 levels in the next three years, and a total cut of 7.5 percent of current GDP over the course of the next decade.

Changes to individual taxes make up the largest source of the revenue loss: about $\$ 1.1$ trillion over the next decade. The lower statutory marginal tax rates, as well as a higher standard deduction and AMT exemptions, are the most significant provisions lowering aggregate tax liabilities for individuals. A variety of other provisions, such as the repeal of the personal exemption, mitigate the overall revenue loss incurred by increasing taxable income. Almost all of the changes to individual taxes are scheduled to expire by $2025 .^{3}$ The projected tax relief for individuals over the next decade adds up to roughly 7.5 percent of personal income at 2017 levels. According to calculations by the Tax Policy Center, TCJA reduces the overall earnings-weighted marginal tax rate by 3.2 percentage points. ${ }^{4}$ Table III in Appendix presenst my own estimates of the impact of the 2017 Act on average marginal tax rates (AMTRs) weighted by broader market income, which show a decrease in the overall AMTR of 2.75 percentage points. This is comparable in magnitude to the immediate AMTR impact of the 1964 Kennedy tax cuts or the 1986 Reagan reform, but with percentage point reductions that are more similar in size across income levels. Both the Tax Policy Center estimates and those in Table III in Appendix likely overstate the impact on marginal tax rates for some higher income taxpayers by not incorporating the cap on the state and local tax deduction imposed by TCJA. ${ }^{5}$

According to the JCT revenue estimates in Table I, the corporate tax cuts lower tax receipts by $\$ 650$ billion. Most significant is the decrease in the corporate tax rate from 35 percent to 21 percent, which in contrast to the cut in individual rates is permanent. The expansion of bonus depreciation, allowing full expensing of certain capital expenditures, is another important source of tax relief for corporations that expires in 2026. The Act provides a number of permanent corporate offsets, such as limits on the deductibility of interest rate expenses and, from 2021 onwards, amortization of R\&D expenditures. As a percentage of 2017 corporate profits, tax liabilities in the aggregate decrease

\footnotetext{
${ }^{3} \mathrm{~A}$ few provisions are permanent, such as those related to the Affordable Care Act, and the switch to the chained price index for indexing the tax brackets.

${ }^{4}$ See http://www.taxpolicycenter.org/model-estimates/conference-agreement-tax-cuts-and-jobs-act-dec-2017/ t17-0323-effective-marginal.

${ }^{5}$ More specifically, this affects change in marginal tax rate of itemizing tax payers that do not pay the alternative minimum tax and pay local taxes exceeding the $\$ 10,000$ cap.
} 
by 7.5 percentage points in 2018, and by 5.8 and 4.9 percentage points in 2019 and 2020 . The projected tax savings for corporations over the next 10 years amount to 29 percent of current annual corporate income. Roughly half of this amount, however, is expected to be offset by the international provisions of the Act.

\section{Time Series Estimates of the GDP Impact of TCJA}

The object of interest in this note is the causal effect $\gamma_{h}$ on GDP growth observed $h \geq 0$ years after a reform of size $\Delta \tau_{t}$ in period $t$, given by

$$
\Delta y_{t+h}=\gamma_{h} \Delta \tau_{t}+\Delta \bar{y}_{t+h}
$$

where $\Delta y_{t+h}$ is future output growth and $\Delta \bar{y}_{t+h}$ is counterfactual future output growth in the absence of the tax reform. In order to use (1) for out-of-sample projections, the tax policy interventions $\Delta \tau_{t}$ in (1) need to be inputs that are measurable in advance, as for instance those in Table I. Also required are estimates of the dynamic causal effects $\gamma_{h}$ associated with these inputs. Such estimates can be obtained from structural macroeconomic models that make explicit assumptions regarding all behavioral responses and general equilibrium effects. The macroeconomic analysis by the Joint Committee for Taxation, for example, makes use of three different structural models. ${ }^{6}$ Alternatively, estimates of $\gamma_{h}$ can be obtained from regression-based models that rely more directly on past experiences with tax changes. Next, I describe the main reduced form models in the recent literature, show how they may be used to make projections about the impact of TCJA, and discuss their interpretation. For brevity, the discussion omits much of the details, which can be found in the studies referenced and in the replication materials available online. ${ }^{7}$

Starting with Romer and Romer (2010), a growing number of studies in empirical macro exploit historical tax reforms as quasi-experiments to identify the effects of tax changes on aggregate economic activity. ${ }^{8}$ Romer and Romer (2010) construct a time series $\Delta \widehat{\tau}_{t}$ containing revenue impact measures as in Table I for all major postwar tax reforms in the US. Estimating $\gamma_{h}$ in (1) by regressing $y_{t+h}$ on $\Delta \widehat{\tau}_{t}$ is, however, problematic since tax reforms are not

\footnotetext{
${ }^{6}$ See publication JCX-69-17 December 22, 2017. The three models are (1) a macroeconomic equilibrium growth model; (2) an overlapping generations model; and a (3) dynamic stochastic general equilibrium model.

${ }^{7}$ See karelmertens.com/research. For an alternative and more comprehensive methodological overview, see also Ramey (2016).

${ }^{8}$ The same approach has been used to study the effects of tax policy changes in the United Kingdom (Cloyne (2013), Cloyne and Surico (2017), Nguyen et al. (2017), Hussain and Liu (2018)), Germany (Hayo and Uhl (2014)), Canada (Lopes (2016), Hussain and Liu (2017)), Spain (Gil et al. (2017)), or multiple countries (Leigh et al. (2014), Riera-Crichton et al. (2012)).
} 
random events. Important determinants of GDP growth, such as government spending or recessionary shocks, also influence tax policy. To avoid problems of simultaneity, Romer and Romer (2010) classify each of the tax reforms by the primary motivation of policy makers on the basis of a variety of historical sources. Next, they construct a series of 'exogenous' tax reforms $\Delta \widehat{\tau}_{t}^{e x o}$, containing only those reforms classified as either ideological or as arising from long-term deficit concerns, while omitting interventions responding to the business cycle or short-term (and typically defense related) government spending changes. Causal effects of tax reforms can be obtained as the least-squares estimates of $\delta_{h}$ in regressions of the form

$$
\Delta y_{t+h}=\delta_{h} \Delta \widehat{\tau}_{t}^{e x o}+u_{t+h}
$$

where $u_{t+h}$ is a residual term. This approach is valid as long as the tax reforms retained in $\Delta \widehat{\tau}_{t}^{e x o}$ are indeed uncorrelated with the residual $u_{t+h}$ capturing all other determinants of output growth in $t+h$. In practice, the $\delta_{h}$ 's can be estimated by separate regressions for every $h$, by a single regression for $h=0$ and additional lags of $\Delta \widehat{\tau}_{t}^{\text {exo }}$ as regressors, or by inverting coefficients of a single regression for $h=0$ and lags of $\Delta y_{t}$ as additional regressors. The regressions may include other control variables, or be part of a system of dynamic equations with many other endogenous variables.

The first three rows of Panel A in Table II presents results for different variants of the direct regression approach in (2). The estimates are not based on the original Romer and Romer (2010) series for $\Delta \widehat{\tau}_{t}^{e x o}$, but on an alternative version proposed by Mertens and Ravn (2012) that omits tax changes with long implementation lags to avoid an additional source of bias. ${ }^{9}$ The models use postwar quarterly data, and the series for $\Delta \widehat{\tau}_{t}^{\text {exo }}$ are static estimates of total revenue impacts as a ratio of GDP in the previous quarters, exactly as in the second row in Table I. The scaling by GDP means that the estimates of $\gamma_{h}$ have the familiar interpretation as 'tax multipliers'. Since almost all of the provisions in TCJA become effective in the 2018 tax year, the Act clearly fits into the category of reforms with short implementation lags included in the Mertens and Ravn (2012) version of $\Delta \widehat{\tau}_{t}^{e x o}$. The motivation for the 2017 Act also seems predominantly ideological, such that it appears reasonable to make use of the estimated effects derived from the exogenous Romer and Romer (2010) tax reforms. The projections in rows 1-3 of panel A of Table II are

\footnotetext{
${ }^{9}$ Tax reforms often legislate tax changes that become only effective with a delay. Mertens and Ravn (2012) provide evidence for anticipation effects on economic activity of pre-announced tax changes, which generally lead to a violation of the exogeneity requirements.
} 
calculated by applying the estimated tax multipliers for each of the three models to a reduction in total tax revenues in the first quarter 2018 equal to $-1.1 \%$ of GDP, as in Table I. The results in the first row are from the distributed lag specification in Romer and Romer (2010). The results in the second row are from a multivariate vector autoregressive (VAR) model that includes $\Delta \widehat{\tau}_{t}^{\text {exo }}$ as an exogenous regressor to each equation, as in Favero and Giavazzi (2012). Finally, the third row shows results for the same VAR model but adding a distributed lag of the $\Delta \widehat{\tau}_{t}^{\text {exo }}$, as in Mertens and Ravn (2012). A full description of the specifications is available in Mertens and Ravn (2014). These three specifications are chosen because they generate results that are representative for the range of estimates typically obtained using the direct regression approach.

Each of the three direct regression approaches yield very similar projections for output growth in 2018, which is predicted to rise by around 1.3 percentage points. The models differ significantly, however, in terms of the dynamics after the first year. The Romer and Romer (2010) model shows a continued positive impact on GDP growth rates through 2019 and 2020 and a total cumulative increase of 2.74 percentage points by 2020. The Favero and Giavazzi (2012) model instead shows a moderate reversal of GDP levels beyond 2018, and a much more modest cumulative three-year growth impact of 0.82 percentage points. Finally, the specification of Mertens and Ravn (2012) yields a positive effect on GDP growth that persists in 2019, a sharp reversal in 2020, and a cumulative three year increase in GDP of 1.39 percentage points.

The other common approaches in the literature can be explained by considering a simple joint system for taxes and output:

$$
\begin{aligned}
\Delta y_{t+h} & =\zeta_{h} \Delta T_{t}+e_{t+h} \\
\Delta T_{t} & =\theta \Delta y_{t}+\Delta \tau_{t}
\end{aligned}
$$

The first equation relates (future) output growth to changes in observable measures of the burden of taxation $\Delta T_{t}$, such as tax revenues (e.g. Blanchard and Perotti (2002)), average tax rates (e.g. Mertens and Ravn (2013)), or average marginal tax rates (e.g. Barro and Redlick (2011)). The second equation makes explicit that these tax measures are endogenous and vary not only because of occasional tax reforms, but also because of changes in economy activity $\Delta y_{t}$. This is obvious when $T$ are tax revenues, but it is also true when using average or average marginal 
tax rates, e.g. because of tax progressivity. Another reason that $T$ is endogenous is that tax policy interventions are also systematically related to $\Delta y_{t}$, for instance by some policy rule. In this case, $\Delta \tau_{t}$ in (4) can be viewed as the (unobserved) residual in such a rule that is uncorrelated with $e_{t+h}$ for $h= \pm 0,1, \ldots$, and with the policy reaction coefficient absorbed in $\theta$. When $\theta \neq 0$, least-squares estimates of $\zeta_{h}$ of (3) are not interpretable as the causal effect of tax changes because of simultaneity. The literature has addressed this identification problem in three alternative ways. Blanchard and Perotti (2002) use an outside estimate of $\theta$ to back out $\Delta \tau_{t}$ as the residual in equation (3), and then use this residual as an instrument to estimate $\zeta_{h}$. Barro and Redlick (2011) or Mertens and Ravn (2014) instead use the Romer and Romer (2010) series $\Delta \widehat{\tau}_{t}^{\text {exo }}$ as an instrument to estimate $\zeta_{h}$. Mertens and Ravn (2014) additionally use the resulting estimate of $\zeta_{h}$ to obtain $e_{t}$ and use it as an instrument to estimate $\theta$. Finally, Caldara and Kamps (2017) use non-tax instruments (e.g. oil or monetary shocks) to estimate $\theta$, and then use the implied residuals in (4) as an instrument to estimate $\zeta_{h}$. In practice, most studies embed the relationships (3)-(4) in richer systems with dynamic terms and more endogenous variables than just output and taxes. The main reason is that required identification assumptions become less stringent, and arguably only plausible, in these richer settings.

Two complications arise when using parameter estimates from (3)-(4) for out-of-sample projections of the impact of tax reforms. Each of these complications becomes clearer after combining both equations to obtain

$$
\Delta y_{t+h}=\left(1-\zeta_{h} \theta\right)^{-1} \zeta_{h} \Delta \tau_{t}+\left(1-\zeta_{h} \theta\right)^{-1} e_{t+h}
$$

The first difficulty stems from a key difference with the direct regression approach in (2), which is that the indirect approaches treat $\Delta \tau_{t}$ as unobserved. Moreover, richer dynamic models identify $\Delta \tau_{t}$ as a macroeconomic 'shock', i.e. as a surprise deviation in taxes from the prior period forecasts that are unrelated to any other structural source of forecast error, such as monetary policy, productivity or financial market shocks. The tax shocks are only more loosely related to historical tax reforms, which are all at least to some degree anticipated prior to enactment. In addition, sizeable tax shocks may also occur when forecasted tax changes are not realized, and the series for $\Delta \tau_{t}^{\text {exo }}$ may also more generally contain measurement error. Any of these concerns causes bias in a direct regression of (5) after replacing $\Delta \tau_{t}$ by $\Delta \widehat{\tau}_{t}^{\text {exo }}$. While the indirect approaches, at least in principle, avoid these problems, one disadvantage is that the tax shocks measured by the residual in (4) are only identified in-sample. This means that, for the purpose of out-of-sample projections, an additional assumption is required regarding the size of the surprise tax 
shock induced by the 2017 tax reform.

TABLE II

ESTIMATES OF THE IMPACT ON REAL GDP GROWTH OF TCJA

\begin{tabular}{llllr}
\hline & & & Cumul. \\
(percentage points) & 2018 & 2019 & 2020 & $2018-20$ \\
\hline
\end{tabular}

A. Impact Based on Tax Multiplier Estimates:

Direct regressions:

Romer and Romer (2010)

Favero and Giavazzi (2012)

$\begin{array}{llll}1.34 & 0.83 & 0.57 & 2.74\end{array}$

Mertens and Ravn (2012)

$\begin{array}{llll}1.23 & -0.11 & -0.30 & 0.82\end{array}$

Mertens and Ravn (2012)

$\begin{array}{llll}1.31 & 1.17 & -1.08 & 1.39\end{array}$

SVAR models:

Blanchard and Perotti (2002)

Mertens and Ravn (2014)

Caldara and Kamps (2017)

\begin{tabular}{rrrr}
0.93 & 0.30 & -0.18 & 1.05 \\
1.57 & -0.09 & -0.36 & 1.13 \\
0.86 & 0.06 & -0.15 & 0.77 \\
\hline & & & \\
1.21 & 0.36 & -0.25 & 1.32
\end{tabular}

Average

Tax Provisions:

B. Impact by Individual and Corporate Tax Provisions:

Mertens and Ravn (2013)

Individual Tax Reform

Business Tax Reform

International Tax Reform

$\begin{array}{llll}0.87 & -0.25 & -0.12 & 0.51\end{array}$

Total

$\begin{array}{rrrr}2.04 & 0.03 & -0.16 & 1.92\end{array}$

\begin{tabular}{llll}
-1.00 & -0.02 & 0.08 & -0.94 \\
\hline
\end{tabular}

Total

$\begin{array}{llll}1.79 & -0.21 & -0.19 & 1.39\end{array}$

C. Impact Based on Responses to Individual Marginal Tax Rates:

Barro and Redlick (2011)

AMTR

1.38

Mertens and Montiel Olea (2018)

AMTR

$\begin{array}{llll}1.29 & 1.01 & 0.13 & 2.44\end{array}$

AMTR and ATR

$\begin{array}{llll}1.38 & 1.07 & -0.05 & 2.39\end{array}$

D. Impact Based on Estimates Allowing for Income Dependence:

Mertens and Montiel Olea (2018)

$\begin{array}{lllll}\text { Top 1\% - Btm 99\% AMTR } & 0.54 & 1.06 & 1.45 & 3.04\end{array}$

Zidar (2018)

$\begin{array}{lllll}\text { Top } 10 \%-\text { Btm } 90 \% & -0.77 & 1.70 & 0.62 & 1.55\end{array}$

Another, more minor, complication arises because of macroeconomic feedback on taxes. Typically, the focus in 
empirical work is on estimates of $\zeta_{h}$, which have the interpretation of causal effects of a tax shock leading to unit change in the measure of taxes of interest, $\Delta T_{t}$. With macroeconomic feedback $\theta \neq 0$, this differs from the effect of a unit change in $\Delta \tau_{t} \cdot{ }^{10}$ However, after establishing the size of the shock induced by the reform, it is the latter that is needed for the purpose of projecting the GDP impact. Equation (5) shows that this projection requires knowledge of $\left(1-\zeta_{h} \theta\right)^{-1} \zeta_{h}$, and therefore not only of $\zeta_{h}$, but also of $\theta$. The distinction is almost automatically relevant, since if $\theta=0$ there would not be an identification problem to begin with. Empirically, it is the case that $\theta>0$ (higher output leads to higher taxes) and $\zeta_{h}<0$ (higher taxes lead to lower output), such that $\left(1-\zeta_{h} \theta\right)^{-1}<1 .{ }^{11}$ In practice, the difference therefore leads to a reduction of the effects relative to those measured by $\zeta_{h}$.

Rows 4-6 in panel A of Table II report results for each of the three indirect approaches outlined above as implemented within a structural vector autoregressive (SVAR) model. The details behind the first two models are available in Mertens and Ravn (2014) and in the online materials. The results in row 6 were kindly provided by Dario Caldara. The estimates shown are for a tax shock that occurs in 2008Q1 and equals the entire revenue impact of $-1.1 \%$ of GDP reported in Table I. The implicit assumption is therefore that the prospects for the eventual tax reform had no influence on economic activity prior to 2017Q4. This assumption is perhaps questionable, as proposals with the basic contours of the reform were made well in advance. On the other hand, the odds of passage in Congress as well as the extent of the cuts in individual taxes remained highly uncertain until very late in the legislative process. ${ }^{12}$ In any case, the projections in rows 4-6 can easily be adjusted to reflect alternative assumptions regarding the size of the tax surprise induced by TCJA.

Panel A of Table II shows that the Blanchard and Perotti (2002) and Caldara and Kamps (2017) identification approaches yield relatively similar projections for GDP growth, which is predicted to increase by around 0.9 percentage points in 2018. The projections of the Mertens and Ravn (2014) model, which uses the Romer and Romer (2010) exogenous reforms for identification, indicate GDP growth that is higher by 1.57 percentage points for 2018 . All three models show relatively small effects beyond 2018, with a slightly more pronounced reversal in the Mertens and Ravn (2014) model. The projected cumulative effect on 2020 GDP levels range from 0.77 to 1.13 percentage points

\footnotetext{
${ }^{10}$ The same distinction is also highlighted in Caldara and Kamps (2017).

${ }^{11}$ In models with more endogenous variables, the effect usually goes the same direction.

${ }^{12}$ Based on the Romer and Romer (2010) exogenous reforms with short implementation lags, Mertens and Ravn (2012) cannot reject the null of no effects on GDP in quarters before enactment, which suggest that anticipation effects during the legislative process are limited.
} 
higher. The final row of Panel A in Table II provides the simple average of the projections of all six tax multiplier models, which shows a growth impact of 1.21 and 0.36 percentage points in 2018 and 2019 respectively. The average of the projections suggest that in 2020 (and beyond), the 2017 Act becomes a modest drag on economic growth.

The tax multiplier models discussed so far only consider the effects of changes in total tax revenues. The usefulness of the resulting projections depends on how similar the TCJA tax change is in terms of persistence and composition to the tax changes identified in the sample by the various models. In the postwar period, federal tax changes have typically either included sunsets or offsetting provisions, or else have been reversed by bracket creep or subsequent legislation. The revenue-to-GDP ratio, as a result, has remained fairly stable, and the projections in Table II implicitly assume a trajectory of future taxes that is correspondingly reverting to average levels. The many sunsets included in the 2017 Act suggest its enactment has generated historical typical expectations for future taxes, at least on the individual side. Important differences in the composition of tax changes relative to other reforms, however, may also matter for determining the growth effects. The remainder of the estimates in Table II provide projections based on a number of additional models that account for different aspects of reforms.

One dimension in which the 2017 Act differs substantially from most other postwar reforms is the magnitude of the business tax cuts. Panel B in Table II shows projections that are based on the baseline model in Mertens and Ravn (2013), which separately identifies the effects of changes in personal and corporate provisions of tax reforms. The identification approach is similar to Mertens and Ravn (2014), but makes use of separate instruments for the individual and corporate provisions of the Romer and Romer (2010) exogenous tax reforms. The identification allows for correlation between personal and corporate tax changes, and exploits heterogeneity in composition across US postwar tax reforms to isolate the dynamic causal effects of each type of tax change. The model only indirectly identifies shocks to both average tax rates, and the projections in Table II use the numbers in Table I as the size of the shocks. Specifically, the first (second) row shows the effects of an unexpected shock of $-0.8 \%(-7.4 \%)$, in the average personal (corporate) tax rate in 2018Q1. Assessing the effects of the international reform is particularly difficult, as it has no historical counterpart in the estimation sample. The projections in panel B for the international provisions, which are based on assuming an additional positive corporate tax shock of $3.6 \%$ in 2018Q1, should therefore be 
interpreted with great caution. ${ }^{13}$ The last row in panel B of Table II shows the combined effect of all provisions implied by the Mertens and Ravn (2014) estimates.

The main implication of accounting for the composition of the 2017 Act in terms of the individual and corporate provisions is that the projection for 2018 GDP growth is noticeably larger at an increase of almost 1.8 percentage points. The predicted three year cumulative impact of 1.39 percentage points, on the other hand, is roughly similar to the average of projections in the tax multiplier models, which indicates a somewhat more pronounced reversal of GDP growth in 2019 and 2020. The projections suggest a relatively large, but short-lived, effect on growth as a result of the business tax reform. This reflects the fact that corporate tax shocks in Mertens and Ravn (2013) are identified largely by transitory changes in the after-tax cost of new investment that can create strong incentives for intertemporal substitution. ${ }^{14}$ Whether such incentives are at currently at play depends on firms' expectations regarding future corporate tax rates and depreciation allowances. In any case, the results are not directly informative about the potential long-run impact of the significant reduction in the corporate tax rate. ${ }^{15}$

Another important feature of the 2017 Act are the substantial cuts in marginal tax rates for individuals, at least in the short run. Panel C in Table II shows projections based on two studies that estimate the growth effects of changes in marginal tax rates rather revenues or average tax rates. These numbers are for the individual tax reform only, and do not incorporate the growth effects of the business and international tax reforms. Identification in both cases relies on using the exogenous Romer and Romer (2010) tax reforms to construct instruments for income-weighted average marginal tax rates (AMTRs). Barro and Redlick (2011) use the original Romer and Romer (2010) average tax rate series, whereas Mertens and Montiel Olea (2018) construct new instruments for changes in AMTRs. The estimate for the Barro and Redlick (2011) model in Table II is obtained by multiplying an AMTR cut of $2.75 \mathrm{pp}$ with an estimated $0.5 \%$ two-year increase in GDP for every pp decrease in the AMTR. ${ }^{16}$ The remaining projections in Panel $\mathrm{C}$ are obtained by assuming a shock to the overall AMTR of -2.75 percentage points, which is based on the calculations in Table III of the Appendix. The first set of projections from Mertens and Montiel Olea (2018) uses a

\footnotetext{
${ }^{13}$ Since the expected revenue increases stem from the repatriation of income at lower rates than the prior statutory rate, it may even be considered to be a cut in taxes.

${ }^{14}$ See Auerbach (1989) and House and Shapiro (2008) for theory and evidence.

${ }^{15}$ See Barro and Furman (2018) for an analysis of the long run growth impact based on neoclassical investment theory.

${ }^{16}$ Note that Barro and Redlick (2011) do not estimate the equivalent of $\theta$ from eqs. (3-4). Therefore, the estimate reported in Table II is in this case not adjusted for scale as discussed, and is instead based directly on the IV estimate of the slope coefficient $\zeta_{h}$. The results in Table II based on Mertens and Montiel Olea (2018) are adjusted to account for macroeconomic feedback effects.
} 
model that only identifies the effects of ATMR shocks. The second set of projections is based on a model that separately identifies the effects of changes in marginal and average tax rates. The methodology in this case is analogous to Mertens and Ravn (2014) with distinct instruments for marginal and average tax rates, while accounting for the fact that both are correlated. Both sets of projections are roughly similar, and suggest a growth impact of around 1.30 percentage points in 2018, and an additional percentage point of GDP growth in 2019. The cumulative three year increase in real GDP is predicted to be around 2.4 percentage points. An estimate of the total growth impact of the TCJA can in principle be obtained by adding the projections in panel $\mathrm{C}$ to those in the second and third rows of Panel B. The main conclusion is that taking into account the substantial cuts in marginal tax rates in the 2017 Act suggests a considerable larger impact on GDP growth than suggested by the tax multiplier models in Panel A.

Most postwar changes to individual tax rates differ substantially by income level, with typically much larger changes in top statutory rates. The 2018 Act differs in that it cuts tax rates more uniformly than is typically the case. The final panel in Table II shows results based on two studies that allow the aggregate effects of tax changes to depend on the distribution of tax changes by income level. Mertens and Montiel Olea (2018) separately identify the effects of shocks to average marginal tax rates for the top $1 \%$ and bottom $99 \%$ income groups, again by adopting the methodology in Mertens and Ravn (2014) with distinct instruments for changes in AMTRs for both groups. The projections in the first row are based on a shock to top 1\% and bottom 99\% ATMRs of -2.66 and -2.78 percentage points respectively, which is based on the calculations in Table III. Zidar (2018) instead follows a direct regression approach based on an extension of the Romer and Romer (2010) series that separates revenue impacts of tax changes affecting the top $10 \%$ and bottom $90 \%$ of the income distribution. The results in Table II uses the estimates reported in Zidar (2018) and assume a 50-50 split between the top 10\% and bottom 90\%, as suggested in a distributional analysis by the Tax Policy Center. ${ }^{17}$ According to the results in Panel D of Table II, the main implication of accounting for the distributional aspects of the 2017 Act is that the growth impact is more delayed, and occurs largely in 2019 and 2020 rather than 2018. The estimates of Zidar (2018) even suggest a negative effect in 2018, although it is based on an estimate that is not statistically significant. By 2020, the Mertens and Montiel Olea (2018) model predicts a level of GDP that is higher by 3 percentage points, while the Zidar (2018) regressions suggest an increase in GDP by about half that amount. As for panel D, an estimate of the total growth impact of the TCJA can be obtained by adding the

\footnotetext{
${ }^{17}$ See http: //www.taxpolicycenter.org/publications/distributional-analysis-conference-agreement-tax-cuts-and-jobsfull.
} 
projections in panel B for the corporate provisions.

\section{Concluding Remarks}

A growing empirical literature in empirical macro focuses on estimating the short to medium-run aggregate effects of federal tax changes. While there is considerable variation in the quantitative findings, there is relatively strong agreement that tax cuts have positive effects on economic activity in the near term. This note applies reduced form estimates from several recent studies to project the impact of the Tax Cuts and Jobs Act on US GDP growth in the next couple of years. The main advantage of this approach is that there is no need to make detailed theoretical assumptions. The structural approaches in use require assumptions on expectations of future tax rates that can be hard to verify, but that are often important in shaping the short-run effects. Reduced form models do not require explicit assumptions regarding the dynamics of expected future tax rates, which are instead part of the estimation. Recent methodological advances also make it possible to account for changes in multiple policy instruments. At the same time, the approach is valid only to the extent the reform is unexpected, exogenous, and reasonably similar to the historical variation and dynamics of tax policy that underlies the model estimates. For these reasons, it is better suited to assess the impact of the individual tax component of TCJA than the impact of the corporate and international tax components. The main conclusion from the projections is that most models yield a sizeable growth effect for 2018, and more modest effects afterwards. The estimates underlying the projections are of course uncertain, and the range of plausible outcomes therefore remains fairly wide. Nevertheless, absent any major macroeconomic shocks, the trajectory of GDP growth observed in the next few years should be informative about the growth effects of tax changes.

\section{References}

Auerbach, Alan J., "Tax Reform and Adjustment Costs: The Impact on Investment and Market Value", International Economic Review 30 (1989), 939-962.

Barro, Robert J., “Tax Reform Will Pay Growth Dividends”, Wall Street Journal Jan. 4, 2018.

Barro, Robert J., "Macroeconomic Effects of the 2017 Tax Reform”, Brookings Papers on Economic Activity, forthcoming

Barro, Robert J. and Charles J. Redlick, "The Macroeconomic Effects of Government Purchases and Taxes", Quarterly Journal of Economics, 126 (2011), 51-102.

Blanchard, Olivier and Roberto Perotti, 2002, "An Empirical Characterization of the Dynamic Effects of Changes in Government Spending and Taxes on Output”, Quarterly Journal of Economics 117 (2002), 1329-1368. 
Caldara, Dario and Christophe Kamps, "The Analytics of SVARs: A Unified Framework to Measure Fiscal Multipliers", Review of Economic Studies 84 (3), 1015-1040

Cloyne, James, "What Are the Effects of Tax Changes in the United Kingdom? New Evidence from a Narrative Evaluation", American Economic Review, 103 (2013), 1507-1528.

Cloyne, James and Paolo Surico, "Household Debt and the Dynamic Effects of Income Tax Changes with Paolo Surico", Review of Economic Studies 84(1) 45-81.

Favero, Carlo and Francesco Giavazzi, "Measuring Tax Multipliers. The Narrative Method in Fiscal VARs". American Economic Journal: Economic Policy 4 (2012), 69-94.

Gil, Paula, Francisco Marti, Richard Morris and Javier J. Pérez and Roberto Ramos, "The Output Effects of Tax Changes: Narrative Evidence from Spain”, Banco de Espana Working Paper No. 1721 (2017).

Hayo, Bernd and Matthias Uhl, "The Macroeconomic Effects of Legislated Tax Changes in Germany", Oxford Economic Papers, 66 (2013), 397-418.

House, Christopher L., and Matthew D. Shapiro, 2008, “Temporary Investment Tax Incentives: Theory with Evidence from Bonus Depreciation” American Economic Review, 98 (2008): 737-768.

Hussain, Syed M. and Lin Liu, "Macroeconomic Effects of Government Spending Shocks: New Narrative Evidence from Canada", manuscript Virginia Commonwealth University (2017)

Hussain, Syed M. and Lin Liu, "Comparing the Effects of Discretionary Tax Changes Between the US and the UK", B.E. Journal of Macroeconomics 18 (2018).

Leigh, Daniel, Andrea Pescatori, and Jaime Guajardo, "Expansionary Austerity New International Evidence", Journal of the European Economic Association, 12 (2013), 949-968.

Lopes, José,“The Federal Tax Multiplier in Canada: a Narrative Approach”, manuscript, Cornell University (2016).

Mertens, Karel and José L. Montiel Olea, "Marginal Tax Rates and Income: New Time Series Evidence”, Quarterly Journal of Economics, (2018), forthcoming.

Mertens, Karel and Morten Ravn, "Empirical Evidence on the Aggregate Effects of Anticipated and Unanticipated US Tax Policy Shocks", American Economic Journal: Economic Policy, 4 (2012), 145-181.

Mertens, Karel and Morten Ravn, "The Dynamic Effects of Personal and Corporate Income Tax Changes in the United States", American Economic Review, 103 (2013), 1212-1247.

Mertens, Karel and Morten Ravn, "A Reconciliation of SVAR and Narrative Estimates of Tax Multipliers", Journal of Monetary Economics, 68 (2014), S1-S19.

Nguyen, Anh D.M., Luisanna Onnis and Raffaele Rossi, “The Macroeconomic Effects of Income and Consumption Tax Changes", Sheffield Economic Research Paper Series No. 2017008 (2017)

Ramey, Valerie A., "Macroeconomic Shocks and Their Propagation", Handbook of Macroeconomics, forthcoming (2016).

Riera-Crichton, Daniel, Carlos A. Vegh and Guillermo Vuletin, 'Tax Multipliers: Pitfalls in Measurement and Identification", Journal of Monetary Economics 79 (2012)

Romer, Christina D. and David H. Romer, "A Narrative Analysis of Postwar Tax Changes", University of California, Berkeley manuscript (2009).

Romer, Christina D. and David H. Romer, "The Macroeconomic Effects of Tax Changes: Estimates Based on a New Measure of Fiscal Shocks", American Economic Review, 100 (2010), 763-801.

Zidar, Owen M., "Tax Cuts for Whom? Heterogeneous Effects of Income Tax Changes on Growth and Employment", Journal of Political Economy, forthcoming 


\section{APPENDIX}

Table III below provides a comparison between the 2017 Tax Act and selected other postwar federal individual tax reforms in terms of the impact on average marginal tax rates. The reforms listed are restricted to those that make immediate and significant changes to individual tax rates and that are classified by Romer and Romer (2009) as exogenous. The AMTR impact estimates are obtained as the difference between a first counterfactual AMTR, calculated using the year $t-1$ income distribution and the new statutory rates and brackets deflated by any automatic adjustments between $t-1$ and $t$, and a second counterfactual AMTR based on the year $t-1$ income distribution and rates and brackets under prior law for year $t$. The income distribution is evaluated at 2015 levels, the most recent year for which data on IRS tax returns is publicly available. For more methodological details, see Mertens and Montiel Olea (2018).

\section{TABLE III}

\section{Estimated Impact on Average MARginal TAX RATE FOR Individuals}

\begin{tabular}{|c|c|c|c|c|c|c|c|c|c|}
\hline & & $\begin{array}{r}\text { All } \\
\text { Tax } \\
\text { Units } \\
\end{array}$ & $\begin{array}{l}\text { Top } \\
1 \%\end{array}$ & $\begin{array}{l}\text { Top } \\
5 \%\end{array}$ & $\begin{array}{r}\text { Top } \\
10 \%\end{array}$ & $\begin{array}{r}\text { Top } \\
5 \% \\
\text { to } 1 \% \\
\end{array}$ & $\begin{array}{r}\text { Top } \\
10 \% \\
\text { to } 5 \% \\
\end{array}$ & $\begin{array}{l}\text { Btm. } \\
99 \%\end{array}$ & $\begin{array}{l}\text { Btm. } \\
90 \%\end{array}$ \\
\hline & In year & & & & & & & & \\
\hline Revenue Act of 1948 & 1948 & -3.38 & -9.14 & -7.07 & -6.07 & -5.24 & -3.68 & -2.67 & -2.06 \\
\hline Revenue Act of 1964 & 1964 & -2.61 & -6.47 & -4.39 & -3.66 & -3.05 & -2.30 & -2.26 & -2.11 \\
\hline Revenue Act of 1978 & 1979 & -1.35 & -0.76 & -0.96 & -1.36 & -1.09 & -2.06 & -1.40 & -1.34 \\
\hline \multicolumn{10}{|l|}{ Economic Recovery } \\
\hline Tax Act 1981 & 1981 & -0.31 & -0.77 & -0.66 & -0.58 & -0.58 & -0.46 & -0.26 & -0.17 \\
\hline Tax Reform Act of 1986 & 1987 & -2.41 & -10.15 & -6.52 & -5.31 & -4.05 & -3.03 & -1.64 & -0.89 \\
\hline \multicolumn{10}{|l|}{ Omnibus Budget } \\
\hline Reconciliation Act of 1990 & 1991 & 0.79 & 2.70 & 1.86 & 1.63 & 1.09 & 1.09 & 0.48 & 0.22 \\
\hline \multicolumn{10}{|l|}{ Omnibus Budget } \\
\hline Reconciliation Act of 1993 & 1993 & 1.08 & 7.43 & 3.45 & 2.45 & -0.28 & 0.13 & 0.09 & 0.17 \\
\hline \multicolumn{10}{|l|}{ Jobs and Growth Tax Relief } \\
\hline Reconciliation Act of 2003 & 2003 & -1.95 & -3.30 & -2.68 & -2.50 & -2.07 & -2.03 & -1.71 & -1.54 \\
\hline Tax Cuts and Jobs Act of 2017 & 2018 & -2.75 & -2.66 & -3.21 & -3.18 & -3.82 & -3.10 & -2.78 & -2.36 \\
\hline
\end{tabular}

Notes. Percentage point differences between a first counterfactual AMTR, calculated using the year $t-1$ income distribution and the new statutory rates and brackets deflated by any automatic adjustments between $t-1$ and $t$, and a second counterfactual AMTR based on the year $t-1$ income distribution and rates and brackets under prior law for year $t$. Top 5\% to 1\% (Top 10\% to 5\%) refers to tax units in the Top 5\% (Top 10\%) but outside the Top 1\% (Top 5\%) of the income distribution. See Mertens and Montiel Olea (2018) for details. Note that the methodology does not account for the cap on deductions of state and local taxes introduced by TCJA. 